\title{
A experiência de discutir inovação e empreendedorismo com estudantes de jornalismo
}

The experience of debating innovation and entrepreneurship with journalism students

La experiencia de discutir la innovación y el emprendimiento con estudiantes de periodismo

(9) Jorge Tarquini

- Mestre em Comunicação Social pela Universidade Metodista de São Paulo

- Docente na Universidade Metodista de São Paulo

- E-mail: jorge.tarquini@espm.br 
$\mathrm{E}$ stranhamento. Essa palavra traduz à perfeição o sentimento reinante no primeiro dia de aula de um longínquo fevereiro de 2012. Era uma turma de sétimo semestre de Jornalismo da Universidade Metodista de São Paulo para a qual eu apresentava uma tal disciplina chamada Empreendedorismo e Gestão - criada em parceria com a Professora Arlete Prieto.

Nenhum curso de Jornalismo no Brasil jamais havia colocado em sua grade algo tão "herege" quanto fazer futuros prêmios Esso (ou Pulitzer, quem sabe?) ter de se dedicar ao tema. A pensar em como seria possível empreender nessa carreira, criar um negócio e falar de negócios ou ganhar dinheiro com Jornalismo. A maioria dos alunos de então enxergava nessa novidade algo deslocado ou inadequado, mero reflexo no mundo acadêmico da influência do "mercado" e a tal "pejotização" - então reinante nas grandes empresas de comunicação. Resumindo: tratar disso como disciplina num curso superior de Jornalismo passou dos milites!

Parecia um pouco demais, por mais que já se discutisse (seriamente) o futuro das empresas de comunicação e a convergência das mídias, que tiravam de suas zonas de conforto jornais, revistas, empresas de TV aberta e fechada e rádios - sem falar do avanço do universo digital, para o qual, diga-se, muita gente não tinha a resposta de "como montar um negócio rentável de conteúdo".

\section{MUDANÇAS PASSARAM DESPERCEBIDAS AOS OLHOS DOS JORNALISTAS}

Naquele momento de 2012, dos 247,2 milhões de celulares registrados no Brasil, apenas 47 milhões eram smartphonese informação mobile era algo ainda "do futuro" ou experimental. Apps, por consequência, iniciavam sua carreira de "populares". Nesse cenário, afinal, empreender em Jornalismo significava o quê? Seria esperado daqueles jovens que criassem novas versões de Abril, Folha, Estadão, Globo? Puro simplismo.

Era premente, já em 2012, discutir como o modelo de negócios do Jornalismo deveria se rever e criar novas oportunidades dentro de um cenário cada vez mais instável e incerto - embalado pelo fato de a informação jornalística ter se tornado apenas um elemento sob o guarda-chuva do "conteúdo" (notícias, entretenimento, publicidade, vendas e mensagens pessoais). Resultado: o público passou a enxergar (e a considerar) o noticiário com os mesmos olhos com os quais via posts em redes sociais.

Opinião e informação não mais se distinguiam uma da outra. E a parede que separava Igreja (redação) do Estado (comercial) ruía a olhos vistos. Sem qualquer bronca do consumidor (que já estava mais do que acostumado a não precisar pagar por qualquer informação). Jornalismo perdendo "valor de face", até mesmo porque, no admirável mundo novo, "conteúdo bom é conteúdo grátis".

Isso tudo apesar de que, naquele momento, ainda engatinhava o universo de aplicativos de informação e produtoras de conteúdo eram vistas como um nome bonitinho para criação de posts, textos para sites, storytelling e releases que seriam enviados para coleguinhas nas redações. Ninguém ainda entendia direito conceitos que ganharam nomes pomposos, como fact checking, inbond journalism, inbound marketing, monitoramento de redes, branded content etc.

Pudera: quem prenunciaria o alcance de inovações como WhatsApp (nascido em 2009) ou Facebook - que, apesar de haver nascido em 2004, ainda disputava espaço com o Orkut (criado apenas onze dias antes do FB!). Instagram, então, nem havia comemorado seu segundo aniversário (6 de outubro) no dia daquela primeira aula, em fevereiro de 2012. YouTube tinha apenas 7 anos e era visto como mero passatempo, enquanto Netflix ainda fazia a transição de entrega de DVDs para o streaming, iniciada em 2007, com somente 23 milhões de assinantes nos EUA. 


\section{ANO 16 • NÚMERO 31 • 2º SEM. 2019 • ORGANICOM

0 Jornalismo (e os jornalistas), por não perceber que discutir modelos de negócio era premente, perdeu alguns (muitos) desses bondes. Deixamos passar a primeira onda das redes sociais, olhamos para o YouTube e para o streaming como curiosidades talvez passageiras, permitimos que a tecnologia do mobile fosse mais importante para que as pessoas pudessem mandar $\mathrm{e}$ receber mensagens pelo WhatsApp.

E assim, sem entender que empreender, no novo cenário, tinha origem em inovação (e não apenas tecnológica, mas de narrativas, de linguagem e de abordagem do conteúdo), o Jornalismo foi se afastando das pessoas, mantendo suas posições nos meios nos quais nasceram. Um vácuo foi deixado nesse universo, em que o "consumidor" de notícias (ou de conteúdo) é quem decide o que quer ver/Ler/ouvir, como ver/ler/ouvir, onde ler/Ler/ouvir e quando ver/ler/ouvir - sem precisar explicar por quê.

Foi nesse vácuo que surgiram novos modelos de negócio empreendedores baseados em conteúdo (jornalístico ou não), no qual surgiram/surgem, cresceram/crescem e brilharam/brilham blogueiros, youtuberse influencers. Uma concorrência poderosa para o Jornalismo e os veículos e negócios tradicionais. E houve ainda outra consequência desse vácuo criado: nele apareceu, cresceu e se estabeleceu o mundo das fake news.

E afirmo isso sem nenhum medo de errar: fomos vítimas do prurido de entender que o que produzimos é produto. E fizemos questão de nem reparar que Jornalismo custa (muito) dinheiro e que era preciso criar novas fontes de receita e modelos de negócio não baseados (pouco) em venda de exemplares e (muita) publicidade. Bastava pautar, reportar, escrever, editar e divulgar bem o que o noticiário. 0 mundo não concordava...

\section{NOVAS GERAÇÕES DE JORNALISTAS TERÃO DE DAR RESPOSTAS AOS ENORMES DESAFIOS DO NEGÓCIO JORNALISMO}

Como apresentar esse enorme desafio dentro de uma sala de aula de Jornalismo? Como sensibilizar estudantes para esse aspecto do exercício do Jornalismo? Como traduzir a revolução no universo do mercado de trabalho do jornalista - para muito além da chorumela do PJ x CLT? Como despertar a curiosidade para novos modelos de negócio e empresas de Jornalismo que inauguravam uma nova era?

Mais do que simplesmente explicar técnicas e teorias de negócios e empreendedorismo, era preciso ir mais longe. Afinal, os manuais de negócios disponíveis tratam de indústrias e serviços que pouco têm a ver com o nosso universo da informação jornalística.

Estudar cases da Procter \& Gamble, da Unilever, de bancos ou de redes de restaurantes não dava conta dos desafios que 0 desmonte que a Quarta Revolução Industrial promovia nas empresas e modelos de negócio de comunicação e Jornalismo. Saía de cena a lógica industrial que fez florescer e crescer as empresas de mídia no século XX e entrava em cena o pensamento pós-industrial. Era preciso construir um olhar e uma base de conhecimento para criar um olhar próprio do empreendedorismo no ambiente do Jornalismo. Colocar o aluno diante de questões objetivas e reais, para que pudesse entender as oportunidades reais ao ter mais esta "habilidade": a de poder empreender.

Uma pessoa com um smartphone nas mãos tem o mesmo poder de produção e difusão de informação que um jornal ou uma TV - e de alcance, caso viralize. E empresas que foram chamadas de "impérios da mídia" começaram a derreter feito sorvete na praia, fosse pela substituição dos meios, fosse pela mudança dos hábitos de consumo de comunicação, fosse por marcas terem trocado anúncios em veículos por mensagens de influencers e microinfluencers. 
Ano a ano, vemos a lista de maiores empresas de mídia do mundo refletindo um movimento inequívoco (e inexorável): nas primeiras posições estão Alphabet (Google, criada por dois estudantes de Stanford, Larry Page e Sergey Brin, em 1998) e Facebook (criado em 2003 pelos universitários de Harvard Mark Zuckerberg, Eduardo Saverin, Dustin Moskovitz e Chris Hughes), enquanto os "impérios" vão escorregando para posições mais baixas. A Amazon está fazendo um esforço enorme para escalar a lista e deixar de ser uma loja, tornando-se uma empresa de comunicação (seu fundador, Jeff Bezos, comprou o jornal Washington Post, em 2013, que, em 2018, foi apontado como a oitava empresa mais inovadora do mundo).

0 que esse ranking e as empresas "neófitas" de comunicação que encabeçam a lista nos mostram? No mínimo, mais uma decorrência da postura olimpiana com que os meios e veículos tradicionais subestimaram (ou apenas ignoraram?) a mudança de cenário. Ainda soa estranho estudar empreendedorismo?

Nem tudo, porém, foi derrocada: havia jornalistas, empreendedores e empresas fazendo a leitura correta do movimento das placas tectônicas que dissolviam a Pangeia da comunicação. Foi exatamente focar nessas novidades para aproximar os estudantes de Jornalismo do empreendedorismo o caminho que escolhi. Com isso, quis despertá-los para um olhar empreendedor (que busca, identifica ou cria oportunidades de negócios) pela junção do bom Jornalismo à inovação dos meios (de produção, difusão e relacionamento com o público) e também a novos modelos de negócio e de financiamento (modos inovadores de pagar a cara conta do bom Jornalismo). Tudo em busca de ter um olhar de futuro para o universo jornalístico.

\section{TREAS FRENTES DO EMPREENDEDORISMO PARA OS FUTUROS JORNALISTAS}

Ao longo dos anos, a revisão sistemática de como abordar o tema empreendedorismo no universo do ensino do Jornalismo levou a questão a um aprimoramento veloz. Isso porque, além da sistematização mais orgânica do assunto, a própria inserção dos alunos no mercado, como estagiários, os fez descobrir todo um novo universo. Sem contar o fato de que implantei a disciplina em outros dois cursos de Jornalismo em grandes escolas: Escola Superior de Propaganda e Marketing (ESPM) (já na sua primeira turma, em 2013) e Faculdade Cásper Líbero (em 2016).

Estudantes de Jornalismo, que antes tinham como opção trabalhar nas grandes empresas/veículos ou em assessorias de imprensa clássicas, hoje experimentam/encontram seu primeiro trabalho em startups baseadas em informação e assessorias de comunicação onde o guarda-chuva do conteúdo e das redes é ressignificado.

Dessa forma, cada elemento apresentado e debatido em sala de aula, assim como o exercício laboratorial de idealizar um novo negócio empreendedor em Jornalismo, reflete o olhar mais apurado (e de menor estranhamento) não apenas para aspectos negociais, mas de linguagem, foco, segmentação, plataforma, distribuição e receita.

No que diz respeito ao "bom Jornalismo", por mais que os modelos clássicos e consagrados de informação, como os grandes jornais, rádios, TVs e portais noticiosos, continuem a gozar de prestígio como fontes confiáveis de informação (e a ainda concentrar o grosso da verba publicitária), talvez a queda em suas tiragens e audiências mostre que é real a renovação do público que consome notícia.

Entre os mais jovens, faz muito mais sentido falar de inovações como Nexo, Jota, Azmina, Vice, Poder 360, Mamilos, Flipboard, BuzzFeed, Agência Pública, Meio, agências de fact-checking como Lupa ou Aos Fatos... Baseados em novos formatos (podcasts, newsletters, reportagens multimídia e interativas, entre outros), eles não são iniciativas de grandes empresas. Ao contrário... 
Apesar do sucesso que alcançam, muitos foram negócios incubados ou acelerados, contaram ou contam com investidores, sponsorse até mesmo financiamento coletivo, por meio de crowdfunding. Muitos não têm receita publicitária - ao menos não de forma clássica: incluem em sua estrutura o espaço para projetos especiais, de branded content, ou conteúdo de marca, que usa as ferramentas do Jornalismo para criar conteúdos relevantes de interesse do público dentro do universo de uma marca (mas, sem necessariamente, falar dela ou de seus produtos).

E já se colhem frutos importantes com esses veículos. 0 mais relevante deles é o resgate do Jornalismo diante de outras formas de informação (ou de mera opinião). São produzidas reportagens de alta qualidade recorrendo a técnicas de jornalismo investigativo e de jornalismo de dados (está aí o Panamá Papers que não me deixa mentir), outras que denunciam problemas políticos, ambientais e sociais e também aquelas que, mesmo fora da pauta hard news do cotidiano, revelam grandes histórias (como a premiada reportagem de Chico Felitti para o BuzzFeed "Fofão da Augusta? Quem me chama assim não me conhece").

Ao analisarmos em sala de aula esses novos veículos e plataformas, entendemos um pouco da nova lógica do Jornalismo pós-industrial, de como o papel do que fazemos pode ultrapassar as antigas fronteiras de audiência e alcançar repercussão e transformação. Tudo dentro dos melhores preceitos do interesse público, da pluralidade, da busca da objetividade e levando os assuntos ao debate com a opinião pública. E, de quebra, empreender em Jornalismo tem se mostrado uma maneira de efetivamente propor novos caminhos para a democratização das mídias e a diversidade de pautas.

Muitos alunos já estão trabalhando nessas novas empresas, nesses novos negócios. E os encaram com naturalidade e não como uma aberração capitalista, criada pela vontade de enriquecer dos empreendedores. Como disse, são operações e negócios com zero vocação (ou vontade) de serem os novos Estadão, Abril, Folha ou Globo. A briga de titãs do século XXI, também aprendemos em sala, hoje é travada por empresas como Amazon, Apple, Google e Facebook - que vão liderar a guerra das empresas do trilhão, iniciada há alguns anos.

O bom jornalismo desses pequenos negócios vai ser a resistência necessária para o domínio dessas trilionárias corporações (que, sem qualquer coincidência, têm investido muito para estabelecer padrões e produzir jornalismo - que eu me permito, aqui, grafar em caixa baixa, pois ainda não sei se merece o "J" maiúsculo. Por enquanto, me encantam mais algumas iniciativas menores já citadas por mim). Ou seja: é preciso haver diversidade de vozes, para que evitemos discursos e visões hegemônicas e também interesses empresariais

As questões ligadas à inovação requerem, em sala de aula, um olhar descontaminado. Por óbvio, o termo desperta imediatamente nas pessoas a relação direta com tecnologia. Porém, nem sempre inovar é sinônimo de invenções modernosas. A inovação pode vir de qualquer aspecto.

Juntos, por meio de pesquisas direcionadas a descobrir inovações no Jornalismo, fazemos uma curadoria que, conscientemente, busca novidades que tragam muito mais do que somente soluções tecnológicas. E, assim, vamos descobrindo inovações como a forma como o Nexo gamifica as vastas numeralhas de dados do IBGE ou da criminalidade, por exemplo. Ou a ideia de utilizar o princípio do Pokemon Go para criar uma plataforma de Jornalismo hiperlocal baseada na captura de notícias ao caminhar pelas ruas.

Em paralelo, estudamos processos de ideação (design thinking, canvas, mapas mentais, prototipagem etc.) que vão mostrar um caminho básico para inovar - fugindo da pura invencionice. E a base para isso está na empatia. Quanto mais eu entender a dor, as vontades, necessidades e desejos de quem quer consumir Jornalismo, mais fácil será criar um novo serviço, produto ou empresa que trará repostas reais para demandas reais. 
Os negócios já existentes, porém, também mostram caminhos de inovação. Ao olharmos para empresas como a Jovem Pan iniciando sua produção audiovisual, ou a Globo divulgando com estardalhaço seus podcasts, percebemos que elas entenderam que precisam inovar: no futuro, nem a Jovem Pan será apenas uma rádio e nem a Globo será apenas uma TV. Se quiserem ter futuro, terão de inovar e se reinventar. Isso também é empreendedorismo. E o mesmo caminho deverá ser trilhado (como já o é) por Folha, SBT, Estadão, Valor Econômico...

Por fim, chegamos em sala ao modelo de negócios. E entra em campo a própria experiência de cada estudante ali presente. Afinal, já pagam pelo Spotify (e aprendem que, se a música é de graça, o modelo freemiumé apenas pagar pela comodidade de pular músicas e ter outros recursos). E também já experimentaram assinar newsletters (gratuitamente ou pagando algum valor). São assinantes do Netflix e sabem identificar negócios baseados em crowdfunding ou receita publicitária. Entendem que não há almoço grátis - principalmente no Jornalismo. E encaram com mais naturalidade a ideia de e-commerces ou market places, branded contente outras coisas que, antes, eram apenas ruídos aos seus olhos e ouvidos.

E assim a disciplina chega à última aula: uma simulação de rodada de negócios, na qual cada "startup" apresenta seu projeto de negócios para um "investidor" - em um pitch de vendas exatamente igual ao que eles encontrarão se algum dia resolverem empreender e apresentar sua ideia a um investidor. São dez minutos apenas. Mas que mostram, claramente, que o estranhamento inicial deu lugar a um orgulho tremendo pelas ideias desenvolvidas - e que podem se tornar uma opção de futuro fora da faculdade. Jornalistas, sim. Empreendedores, por que não? 